\title{
Discussing End-of-Life Issues in the Last Months of Life: A Nationwide Study among General Practitioners
}

\author{
Ebun Abarshi, M.D., ${ }^{1,2}$ Michael Echteld, Ph.D., ${ }^{1,2}$ Gé Donker, M.D., ${ }^{3}$ Lieve Van den Block, Ph.D.,, ${ }^{4,5}$ \\ Bregje Onwuteaka-Philipsen, Ph.D.,,2 and Luc Deliens, Ph.D., ${ }^{1,2}$
}

\begin{abstract}
Background: Communication is a necessary tool for ensuring the provision of quality patient-centered care for patients who have life-threatening illnesses, and discussing all relevant end-of-life issues should not be limited to cancer patients.

Objective: To examine the incidence and timing of general practitioners (GPs) discussing end-of-life issues with patients whose deaths were expected, and to identify the factors associated with them discussing these issues. Methods: Between January and December 2008, GPs participating in a nationally representative sentinel surveillance network of GPs were asked to register, using standardised forms, the extent of discussing 10 end-of-life issues with patients.

Results: We examined 252 patients who died nonsuddenly, 38\% of whom died of cancer, and $86 \%$ of whose treatment goal was palliative care. Our findings show that GPs often waited until very close to death before they discussed end-of-life issues with patients, and discussed spiritual and social issues less than physical symptoms, diagnoses, and psychological problems. In 74\% of cases, the GPs were informed of their patients' preferred place of death; and 8 out of 10 patients with known preferences for place of death, died there. Being diagnosed with cancer was associated with a higher frequency of discussing all 10 end-of-life issues than diagnosis with other (noncancer) conditions, but this is a state of mind we did not explore in this study.

Conclusion: Promotion of timely discussion of all relevant end-of-life issues, in patients with cancer and noncancer diagnoses, is advisable based on systematic needs assessment.
\end{abstract}

\section{Introduction}

A T THE END OF LIFE, communication is a key tool for identifying, assessing, and relieving illness burdens, ${ }^{1,2}$ and for providing patient-centered care. ${ }^{3}$ At such times, preferences for information and communication differ, depending on individual patient characteristics ${ }^{4,5}$ and the symptoms they experience. ${ }^{6,7}$ Failure to discuss end-of-life issues can affect the quality of palliative care for patients and their families. ${ }^{6,8}$ Understandably, some issues are more pressing at certain periods in the course of illness, ${ }^{1,2}$ and may prompt more frequent discussions. ${ }^{2,4}$ However, content, extent, and changes in patient needs are best assessed and addressed through adequate communication of relevant topics. Studies show that many patients with life-threatening illnesses may have unmet information needs. ${ }^{1,2,7,9}$
In the Netherlands, the gate-keeping function of general practice is highly developed, such that virtually all patients are registered with a general practitioner (GP), whose referral is required for accessing specialized medical services. ${ }^{10,11}$ GPs provide basic end-of-life care for patients living at home and in residential care homes, ${ }^{11}$ and could play a key role in communicating end-of-life issues with the terminally ill. ${ }^{12}$ First, they have a contextual knowledge of the patients and the family dynamics, given that their work is communitybased. Second, they manage the pain and other burdens that accompany end-stage disease, ${ }^{13,14}$ can provide at-home care for patients and their caregivers, ${ }^{15,16}$ and maintain continuity of care between disciplines ${ }^{13,17,18}$ and settings. ${ }^{18-22}$

Cartwright et al. surveyed GPs and specialists in Australia and six European countries on the extent to which they discussed end-of-life issues with terminally ill patients. ${ }^{4}$ Their

\footnotetext{
${ }^{1}$ The EMGO Institute for Health \& Care Research (EMGO+), Department of Public and Occupational Health, VU University Medical Center, Amsterdam, The Netherlands.

${ }^{2}$ Palliative Care Center of Expertise, Amsterdam, The Netherlands.

${ }^{3}$ NIVEL, Netherlands Institute for Health Services Research, Utrecht, The Netherlands.

${ }^{4}$ End-of-Life Care Research Group, Vrije Universiteit Brussel, Brussels, Belgium.

${ }^{5}$ Department of General Practice, Vrije Universiteit Brussel, Brussels, Belgium.

Accepted October 18, 2010.
} 
results show that in the Netherlands, GPs "in principle, always" discuss aspects of the disease with patients in $>90 \%$ of cases, whereas they "in principle, always" discuss social and spiritual problems in $60 \%$ and $26 \%$ of cases, respectively. However, these were assessments of how GPs discussed these topics in general, because they were not focused on specific patients. Asking about how one would act in an instance is especially vulnerable to receiving socially desirable responses. Also, previous studies had been limited to physician intentions ${ }^{6,23,24}$ and diagnoses. ${ }^{2,6,9,25}$ This is the first nationwide study that asks GPs about the end-of-life issues they had discussed with actual patients. Using a surveillance network of GPs, ${ }^{26-28}$ we examined the incidence and timing of discussing end-of-life issues with respect to three intervals before death (before the last month, in the last 2-4 weeks, in the last week) with patients whose deaths were expected, and identified factors associated with discussing 10 issues: primary diagnosis, incurability of illness, life expectancy or prognosis, possible medical complications, physical symptoms, psychological problems, social problems, spiritual or existential problems, palliative care options, and treatment burdens.

\section{Methods}

\section{Selection and procedure}

Between January and December 2008, patients' deaths were registered via a sentinel network of GPs, nationally representative of practicing GPs. ${ }^{26}$ The network comprised 65-70 GPs from 45 practices, and covered close to $1 \%$ of the registered patient population. ${ }^{27,28}$ The GPs received a structured registration form one week after a patient $(\geq 1$ year) died, with a request to fill and return it. If necessary, they also received reminders. ${ }^{26,27}$ Based on the question, "Was death sudden and unexpected?", all sudden deaths (i.e., with a "yes" response) were excluded on the premise that such patients did not received palliative care from their GP. Patients were classified based on their place of death: in the nursing home, in their homes, in a care home, or in a hospital (a care home death was death that occurred in a care home setting). All patients who died in the nursing home were excluded from this study because medical care in Dutch nursing homes was provided by specialists, and not by the GP; however, the GP managed the care of patients at home and in care homes until death (the selection process is presented in Fig. 1). Lastly, "dying in a preferred place" was derived in three different steps-we asked the GPs if they were aware of their patients' preferred place of death; requested for the place of death as reported in patient's death registration, and checked for congruence between both sets of variables. Expectedly, "dying in a preferred place" could not be derived for those patients whose GPs were unaware of their preferred place of death.

The data collection process was supervised by NIVEL (the Netherlands Institute of Health Services Research), using a standardised protocol. ${ }^{29}$ Participating GPs returned their forms to NIVEL, where they were scrutinized for errors and missing data, and missing data were retrieved by telephone contact. Next, the forms were duplicated and sent to the researchers for data entry and analyses.

An ethical review was not required by the Dutch law because data were collected after the death of patients. More details on the methodology of this study have been published elsewhere. $^{27}$

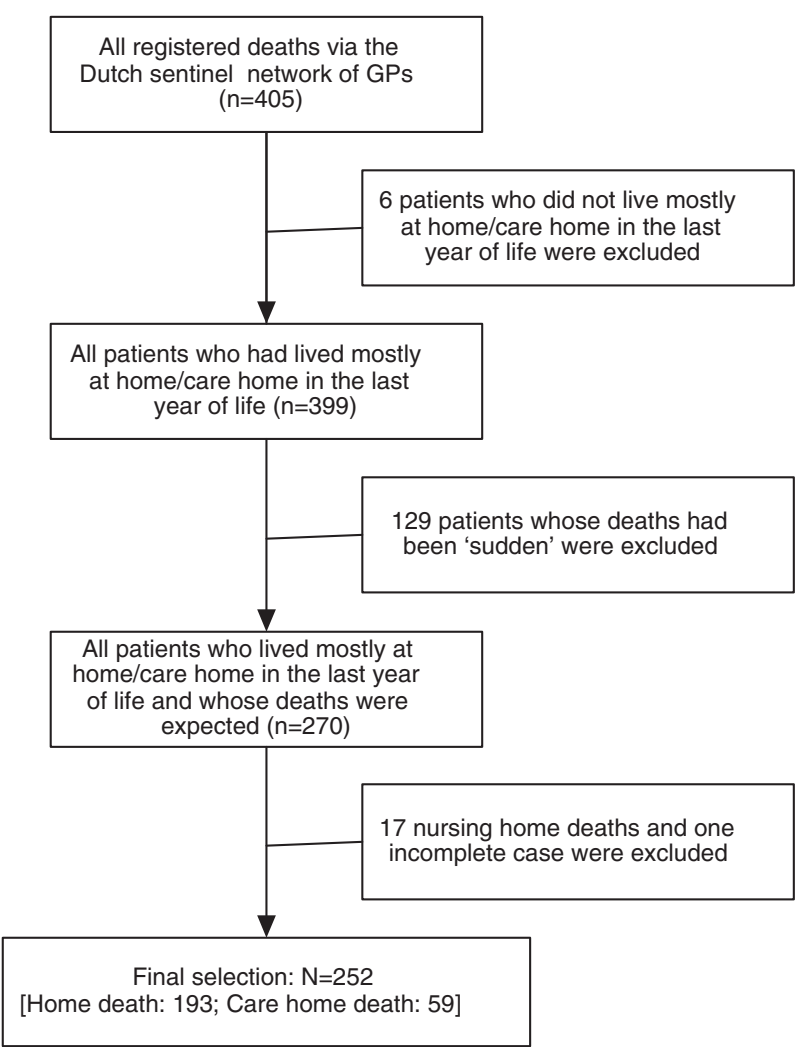

FIG. 1. Flow chart illustrating the selection process.

\section{Research instrument}

The research instrument, a 21-item registration form consisting of multiple-choice and open-response questions, was designed to explore socio-demographic characteristics, causes of death (as recorded in the death certificate), and end-of-life care characteristics. We used it to survey place of care/death; involvement of a multidisciplinary palliative care team; hospital/intensive care unit (ICU) admissions in the last 3 months of life; GP home visits or personal contacts (excluding telephone calls) made in the last 3 months, last $2-4$ weeks, and within the last week of life; treatment goal in the last week of life (curative, life-prolonging, or palliative); dementia/coma; functional state in the last week of life using the Eastern Cooperative Oncology Group (ECOG) performance scale ${ }^{30}$; symptom frequency and distress in the last week of life using the Memorial Symptom Assessment Scale (MSAS) ${ }^{31}$; and patient's preferred place of death. Every year, new questions were tested among some sentinel GPs using interviews, to ensure comprehensibility and acceptability. When the GPs did not understand the concepts in the registration form as intended, revisions were made. In addition, operational definitions were provided so that respondents understood exactly how to approach the different items in the forms.

The GPs were asked to specify whether they had discussed primary diagnosis, incurability of illness, life expectancy or prognosis, possible medical complications, physical symptoms, psychological problems, social problems, spiritual or existential problems, palliative care options, and treatment burdens with the terminally ill patient in question. These issues had been derived from a cross-national survey of 
physicians by Cartwright et al. ${ }^{4}$ Each issue was explored in three stipulated time intervals using a multiple-choice answer format. Options available included "never discussed," "discussed before last month of life," "discussed 2-4 weeks" (i.e., before the last week of life, but within the last month of life), "discussed in the last week," and "question not applicable." It was possible to select more than one answer per issue.

\section{Statistical analysis}

Statistical computations were done using SPSS 15.0 (SPSS Inc., Chicago, IL). From the three answer categories provided, we calculated the interval in which each end-of-life issue was discussed for the very first time, and the frequency of discussing this in the three stipulated time intervals (Table 1). We used Pearson's $\chi^{2}$ test to analyse whether several patient and care characteristics were associated with the different end-oflife issues ever being discussed. We chose patient and care characteristics that were found relevant from literature ${ }^{2,32-35}$ : age, gender, education, cancer diagnosis, presence of dementia and treatment focus (Table 2).

Separately, we analysed the dimensionality of the issues, using principal component analyses, ${ }^{4}$ and this indicated a unidimensional scale with components that explained $52 \%$ and $64 \%$ of the variance, and a Cronbach $\alpha$ of 0.90 and 0.94 , respectively. Removal of any one of the 10 issues did not alter the $\alpha$ values.

Next, we constructed two scales ("ever discussed end-oflife issue," and "discussed end-of-life issue in last week of life") as dependent variables, and computed the total mean for all 10 end-of-life issues. Too explore which patient and carerelated characteristics are independently associated with the single (mean) communication scale per the two abovementioned time intervals, we performed univariate and multiple regression analyses using the backward elimination method (Table 3).

\section{Results}

\section{Characteristics of study population}

Patients' demographic, clinical, and care characteristics are shown in Table 4. We registered a total of 252 nonsudden deaths, representative of all deaths outside those in the nursing homes and hospitals. Mean age was 77 years (standard deviation [SD] 15.8), 55\% were female, and $48 \%$ had little or no elementary education. GPs were informed of patients' preferred place of death in $74 \%$ of cases. Cancer was the cause of death in 38\%, dementia was diagnosed by GP/physician in $12 \%$, and about 9 in 10 patients had a "palliative care" treatment goal, in the last week of life.

\section{Incidence and timing of discussing end-of-life issues}

Table 1 shows that all but spiritual/existential problems were discussed by more than half of the GPs. Physical symptoms were discussed most frequently (73\%) in the three stipulated time intervals. Four main patterns of discussing end-of-life issues were observed before the last month to the last week of life; physical symptoms, life expectancy, and palliative care options were discussed more frequently in the last 2-4 weeks, and slightly less frequently in the last week of life; psychological problems, medical complications, and social problems were discussed at about the same frequency before the last month and in the last 2-4 weeks, but less frequently in the last week of life; primary diagnosis and incurability were discussed progressively less frequently toward death; whereas treatment burdens and spiritual/ existential problems were discussed most in the last 2-4 weeks, and least in the last week of life. The differences in discussing each issue were few and far between per time interval, and only for three cases did a GP discuss all 10 end-oflife issues before death.

Table 1. Percentages of Patients Whose GPs Discussed End-of-life Issues "Ever" And in Three Time Periods before Death $(N=252)^{\mathrm{a}}$

\begin{tabular}{|c|c|c|c|c|c|c|c|}
\hline \multirow[b]{3}{*}{$\begin{array}{l}\text { End-of-life issues discussed } \\
\text { with patients }\end{array}$} & \multirow{3}{*}{$\begin{array}{l}\text { Discussed } \\
\text { "ever" before } \\
\text { death }(\%)\end{array}$} & \multicolumn{6}{|c|}{$\begin{array}{c}\text { Answer categories for the timing of GPs discussing } \\
\text { the end-of-life issues with patients }\end{array}$} \\
\hline & & \multicolumn{2}{|c|}{$\begin{array}{l}\text { Before the last } \\
\text { month of life }(\%)\end{array}$} & \multicolumn{2}{|c|}{$\begin{array}{c}\text { Within the last } 2-4 \text { weeks } \\
\text { of life }(\%)\end{array}$} & \multicolumn{2}{|c|}{$\begin{array}{c}\text { In the last week } \\
\text { of life }(\%)\end{array}$} \\
\hline & & Total $^{\mathrm{b}}$ & $\begin{array}{l}\text { Very first } \\
\text { time }\end{array}$ & Total $^{\mathrm{b}}$ & $\begin{array}{l}\text { Very first } \\
\text { time }\end{array}$ & Total $^{\mathrm{b}}$ & $\begin{array}{l}\text { Very first } \\
\text { time }\end{array}$ \\
\hline 1. Physical symptoms & 73 & 45 & 45 & 50 & 17 & 47 & 11 \\
\hline 2. Life expectancy (prognosis) & 69 & 33 & 33 & 38 & 22 & 37 & 14 \\
\hline 3. Psychological problems & 67 & 39 & 39 & 39 & 16 & 35 & 11 \\
\hline 4. Primary diagnosis & 62 & 40 & 40 & 34 & 11 & 33 & 11 \\
\hline 5. Incurability of illness & 61 & 39 & 39 & 35 & 13 & 30 & 9 \\
\hline 6. Palliative care options & 59 & 29 & 29 & 33 & 16 & 32 & 14 \\
\hline 7. Possible medical complications & 55 & 28 & 28 & 28 & 16 & 25 & 9 \\
\hline 8. Treatment burdens & 55 & 27 & 27 & 29 & 15 & 24 & 12 \\
\hline 9. Social problems & 51 & 29 & 29 & 29 & 15 & 22 & 7 \\
\hline 10. Spiritual/existential problems & 27 & 13 & 13 & 16 & 9 & 11 & 4 \\
\hline
\end{tabular}

aPercentages of missing observations variables ranged between $0.4 \%$ and $5.6 \%$.

${ }^{b}$ More than one answer possible per the three time intervals before death.

GP, general practitioner. 


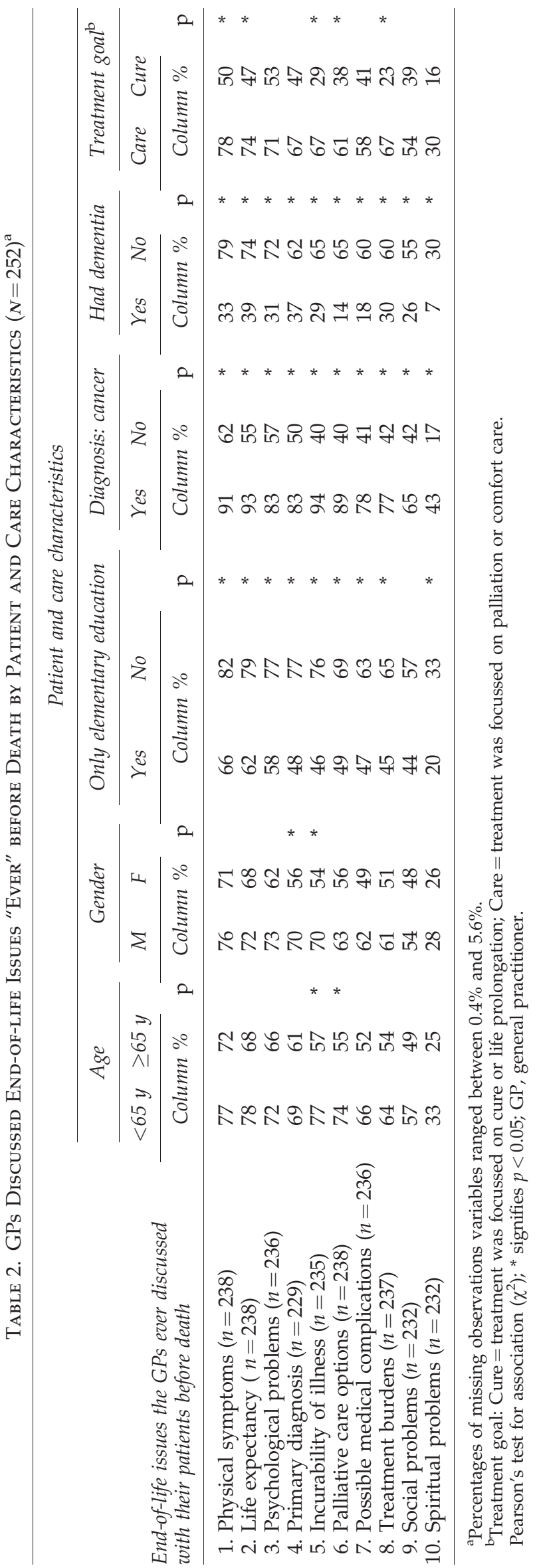

\section{Patient characteristics of ever discussing end-of-life issues}

Table 2 relates the rate of ever discussing end-of-life issues to specific patient and care characteristics (age, gender, education, cancer diagnosis, presence of dementia, and treatment focus). Differences exist in discussing incurability of illness and palliative care options-both were discussed more frequently with patients under 65 years $(77 \%$ and $74 \%$, respectively) than with those over 65 years $(57 \%$ and $55 \%$, respectively). Primary diagnosis and incurability were discussed more frequently with men (both 70\%) than women (56\% and $54 \%$, respectively). GPs discussed significantly more frequently all end-of-life issues (except social problems) with more educated patients. Also, all end-of-life issues were discussed significantly more frequently with cancer than noncancer patients, but significantly less frequently with dementia patients than patients without dementia, with a difference of up to $50 \%$ for discussing palliative care options (14\%:65\%). In addition, some issues were discussed significantly more frequently when the treatment goal was palliative care: physical symptoms $(78 \%$ and $50 \%$, respectively), life expectancy ( $74 \%$ and $47 \%$, respectively), incurability of illness (67\% and $29 \%$, respectively), palliative care options $(61 \%$ and $38 \%$, respectively), and treatment burdens (67\% and $23 \%$, respectively).

\section{Factors associated with discussing end-of-life issues: Ever and in the last week of life}

Table 3 shows results from linear regression analyses relating patient and care characteristics to the aggregate mean score for ever discussing and discussing all end-of-life issues in the last week of life. On univariate analyses, ever discussing end-of-life issues was positively associated with cancer, GP being informed of a patient's preferred place of death, GPpatient contact in the last 3 months of life, having higher education, and using palliative care initiatives. Ever discussing end-of-life issues was inversely associated with dementia, more ICU admissions, and older age. The multivariate analyses show ever discussing end-of-life issues to be significantly associated with cancer, GP informed of a preferred place of death, not having dementia, GP-patient contact in the last 3 months of life, and fewer ICU admissions. Treatment goals and symptom distress were not assessed prior to the last month of life given the wide spectrum of diagnoses examined.

In the last week of life, the aggregate mean score for ever discussing the end-of-life issues was associated with GP-patient contact in the last 3 months of life, cancer, GP informed of a preferred place of death, higher education, the use of palliative care initiatives, having a palliative care treatment goal, pain, lack of energy, constipation, and lack of appetite. Ever discussing end-of-life issues was inversely associated with dementia, treatment goal being cure or life prolongation, having more ICU admissions, and being male. On multivariate analyses, ever discussing end-of-life issues was significantly associated with cancer and the absence of dementia.

\section{Discussion}

Altogether we examined 252 patients whose deaths were nonsudden and foreseen by GPs of the Dutch sentinel national network. In each of three time intervals, physical and psy- 
Table 3. Determinants of GPs Discussing All End-of-life Issues “Ever" before Death ANd One Week Before Death $(N=252)^{a}$

\begin{tabular}{|c|c|c|c|c|}
\hline \multirow[b]{3}{*}{ Associated factors } & \multicolumn{4}{|c|}{ Standardized regression coefficients } \\
\hline & \multicolumn{2}{|c|}{ Ever before death } & \multicolumn{2}{|c|}{ One week before death } \\
\hline & Univariate & Multivariate & Univariate & Multivariate \\
\hline \multicolumn{5}{|c|}{ Factors measured with regards to the period 'one-three months' before death } \\
\hline Age & $-0.18^{*}$ & & -0.10 & \\
\hline Gender $($ male $=1$; female $=0)$ & -0.13 & & $-0.14^{*}$ & \\
\hline Education level & $0.24^{*}$ & & $0.25^{*}$ & 0.16 \\
\hline Cause of death cancer $($ cancer $=1$; not cancer $=0$ ) & $0.46^{*}$ & $0.32^{*}$ & $0.33^{*}$ & $0.20^{*}$ \\
\hline Cause of death cardiovascular disease & $-0.17^{*}$ & & -0.05 & \\
\hline Diagnosis: dementia & $-0.32^{*}$ & $-0.25^{*}$ & $-0.22^{*}$ & $-0.22^{*}$ \\
\hline Number of hospital admissions & -0.004 & 0.12 & -0.04 & \\
\hline Number of ICU admissions & $-0.25^{*}$ & $-0.15^{*}$ & $-0.18^{*}$ & \\
\hline Palliative care was used & $0.20^{*}$ & & $0.15^{*}$ & \\
\hline GP-patient contact 3 months before death & $0.37^{*}$ & $0.16^{*}$ & $0.34^{*}$ & \\
\hline GP informed about patient's preferred place of death & $0.45^{*}$ & $0.25^{*}$ & $0.31^{*}$ & 0.18 \\
\hline \multicolumn{5}{|c|}{ Factors (symptom distress ${ }^{\mathrm{b}}$ measured with regards to the period "one week" before death } \\
\hline Treatment goal: cure or life prolongation & & & $-0.19^{*}$ & \\
\hline Treatment goal: palliative care & & & $0.22^{*}$ & \\
\hline Functional status & & & 0.01 & \\
\hline Lack of appetite & & & $0.19^{*}$ & \\
\hline Lack of energy & & & $0.20^{*}$ & \\
\hline Pain & & & $0.22 *$ & \\
\hline Drowsy & & & 0.06 & \\
\hline Constipated & & & $0.20^{*}$ & \\
\hline
\end{tabular}

a Percentages of missing observations variables ranged between $0.4 \%$ and $5.6 \%$; ${ }^{*} p<0.05$; significance levels for the $t$ statistics.

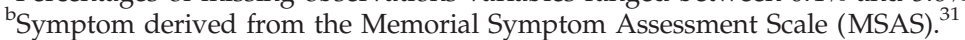

ICU, intensive care unit; GP, general practitioner.

chological problems were discussed most frequently, whereas social and spiritual issues were discussed least frequently. GPs, in more than one third of cases, discussed physical symptoms, diagnosis, psychological problems, and incurability of illness and prognosis for the very first time before the last month of life, whereas in about $10 \%$ of cases, they discussed incurability of illness, possible medical complications, and social and spiritual problems for the very first time in the last week of life. All 10 end-of-life issues were discussed only with three patients. There were relatively more discussions with more educated patients, cancer patients, patients without dementia, and those for whom the treatment goal was palliative care. Cancer was most frequently associated with discussing all end-of-life issues before the last month, in the last 2-4 weeks, and in the last week of life. Cancer, not having dementia, GP's knowledge of preferred place of death, GP-patient contact, and not being admitted to the ICU were the only independent associated factors for ever discussing the end-of-life issues.

To the best of our knowledge, this is the first nationwide study that seeks to explore the incidence of actual GP-patient communication at the end of life. From a general patient-population, we made a selection of all patients who we felt could have benefited from planned terminal care. Via an existing surveillance network, we enlisted trained GPs, representative of all GPs nationally, so as to produce results that could reflect the actual state of affairs in the Netherlands. However, one limitation was the fact that we could not combine the GP characteristics with the patient cases. Also, given the retrospective nature of the study, there might have been some recall bias. We limited the chances of this by sending the registration form one week after a patient's death. Another drawback was that the GPs self-reported on the care they had provided, and even though we asked about actual behavior, it is possible that they provided "ideal responses" in some instances, or simply conceptualized some themes, for example, "treatment burdens" in ways different from what we expected. We did not explore whether some of the undiscussed issues had in fact been adequately communicated to the patients by other care providers, because that was outside our research question, and we did not examine plausible demographic or clinical predictors among patients who appear to have had the issues brought up "for the very first time" in less than one month prior to death, because of the lack of power.

Our findings show that GPs often wait until very close to death before discussing end-of-life issues, that cancer patients receive a greater focus than patients with dementia or other chronic conditions, and that GPs generally avoid social and spiritual issues compared with physical symptoms. ${ }^{36,37}$ The former is in consonance with results from Cartwright et al., who showed Dutch GPs as discussing end-of-life issues more often, compared with GPs from Australia and six other Western European countries. ${ }^{4}$ This could be related to the open debate on end-of-life issues in the Netherlands, and the congruence in results may suggest that intentions and actual behavior match, in this instance. The relative lack of GPs discussing spiritual issues is not surprising, but contrasts substantially with the importance patients place on their GPs broaching spiritual issues. ${ }^{38}$ Cancer was the main diagnosis that strongly correlated with discussing all the end-of-life 
Table 4. Patients' Demographic, Clinical, and Care Characteristics $(N=252)^{a}$

\begin{tabular}{|c|c|}
\hline Characteristics & $\%$ \\
\hline \multicolumn{2}{|l|}{ Age range } \\
\hline \multicolumn{2}{|l|}{$<64 \mathrm{y}$} \\
\hline \multicolumn{2}{|l|}{$65-84$ y } \\
\hline \multicolumn{2}{|l|}{$\geq 85 \mathrm{y}$} \\
\hline \multicolumn{2}{|l|}{ Gender } \\
\hline \multicolumn{2}{|l|}{ Male } \\
\hline \multicolumn{2}{|l|}{ Female } \\
\hline \multicolumn{2}{|l|}{ Education level } \\
\hline \multicolumn{2}{|l|}{ Primary or less } \\
\hline \multicolumn{2}{|l|}{ Secondary or equivalent } \\
\hline \multicolumn{2}{|l|}{ Tertiary or equivalent } \\
\hline \multicolumn{2}{|l|}{ Cause of death } \\
\hline \multicolumn{2}{|l|}{ Cancer } \\
\hline \multicolumn{2}{|l|}{ Cardiovascular disease } \\
\hline \multicolumn{2}{|l|}{ Others (including COPD, renal failure, liver disease) } \\
\hline \multicolumn{2}{|l|}{ Dementia diagnosed } \\
\hline \multicolumn{2}{|l|}{ Number of hospital admissions in the last 30 days of life } \\
\hline \multicolumn{2}{|l|}{ None } \\
\hline \multicolumn{2}{|l|}{ One } \\
\hline \multicolumn{2}{|l|}{ Two or more } \\
\hline \multicolumn{2}{|l|}{ Number of ICU admissions in the last 30 days of life } \\
\hline \multicolumn{2}{|l|}{ None } \\
\hline \multicolumn{2}{|l|}{ One } \\
\hline \multicolumn{2}{|l|}{ Two or more } \\
\hline \multicolumn{2}{|l|}{ Patient received palliative care initiatives in the last 3 months } \\
\hline \multicolumn{2}{|l|}{ Patient was visited/contact by GP (excluding phone calls) in the last 3 months } \\
\hline \multicolumn{2}{|l|}{ Patient's GP was informed of his/her preferred place of death } \\
\hline \multicolumn{2}{|l|}{ Patient died in his/her preferred place of death (i.e., of those with known preferences) } \\
\hline \multicolumn{2}{|l|}{ Patient's treatment goal in last week of life was mainly } \\
\hline Palliative care & 86 \\
\hline Cure or life-prolonging & 14 \\
\hline
\end{tabular}

${ }^{a}$ Percentages of missing observations variables ranged between $0.4 \%$ and $5.6 \%$.

COPD, chronic obstructive pulmonary disease; GP, general practitioner; ICU, intensive care unit.

issues, although cardiovascular disease was still a major cause of death in this population. Given the predictability of its trajectory, ${ }^{39}$ we know that cancer opens up people for discussing end-of-life issues. However, patients with cardiovascular and other chronic illnesses have palliative care needs that may not always be obvious,, 39 and also have much need for adequate and timely information. ${ }^{9,40,41}$ Finally, about a quarter of the patients studied had GPs who were not aware of their preferred place of death, compared with $46 \%$ of patients in a similar selection from a previous dataset. ${ }^{27}$ This rise in GP awareness may have been as a result of the regular feedback participating GPs received, following analysis of the SENTI-MELC study datasets. In both instances, a patient was 4 times more likely to die in a preferred place when the GPs had been informed of his/her preference. ${ }^{26,27,42,43}$

In conclusion, cancer remains the main reason for discussing end-of-life issues in the Netherlands. It has been widely stated in literature that palliative care provision, which includes discussing end-of-life issues, should not be limited to cancer patients. ${ }^{8,9,12}$ This message should be extended to physicians in palliative care training. Because there is substantial disease-specific variation in the end-of-life trajectory, promotion of timely discussion of all important end-of-life issues, including spiritual and social issues, is advisable. A useful tool that GPs can utilize to determine when such discussion is appropriate for a specific patient is the question,
"Would I be surprised if this patient would not live any more than a year or half a year from now," which is used in the UK in the Gold Standards Framework. ${ }^{44}$

\section{Acknowledgments}

This work was financially supported by the Belgian Institute for the Promotion of Innovation by Science and Technology in Flanders (grant no. SBO IWT 050158), as a strategic and comparative research project. Our sponsors played no role in the design or conduct of the study; collection, management, analyses, or interpretation of the data; or in the preparation, review, or approval of this article. The corresponding author, together with the co-authors, had full access to all the data used, and have the final responsibility for the decision to submit this article for publication.

We thank all sentinel GPs in the Netherlands for participating in this study and for providing relevant data; Mrs. Marianne Heshusius of the Netherlands Institute for Health Services Research (NIVEL) for supervising the data collection process; and Ms. Ingeborg Deerenberg of the Netherlands Central Bureau of Statistics, for providing national mortality rates on subpopulations.

\section{Author Disclosure Statement}

No competing financial interests exist. 


\section{References}

1. WHO: National Cancer Control Programmes: Policies and guidelines. Geneva: World Health Organization, 2002.

2. Rutten LJ, Arora NK, Bakos AD, Aziz N, Rowland J: Information needs and sources of information among cancer patients: A systematic review of research (1980-2003). Patient Educ Couns 2005;57:250-61.

3. Winzelberg GS, Hanson LC, Tulsky JA: Beyond autonomy: Diversifying end-of-life decision-making approaches to serve patients and families. J Am Geriatr Soc 2005;53:10461050.

4. Cartwright C, Onwuteaka-Philipsen BD, Williams G, Faisst K, Mortier F, Nilstun T, Norup M, van der Heide A, Miccinesi G: Physician discussions with terminally ill patients: A cross-national comparison. Palliat Med 2007;2:295-303.

5. Crawley LM, Marshall PA, Lo B, Koenig BA: Strategies for culturally effective end-of-life care. Ann Intern Med 2002;136:673-679.

6. Gaston CM, Mitchell G: Information giving and decisionmaking in patients with advanced cancer: A systematic review. Soc Sci Med 2005;61:2252-2264.

7. Heyland DK, Tranmer J, O'Callaghan CJ, Gafni A: The seriously ill hospitalized patient: Preferred role in end-of-life decision making? J Crit Care 2003;18:3-10.

8. Abraham A: Lack of communication affects the care of patients and families. Prof Nurse 2004;19:351-353.

9. Harding R, Selman L, Beynon T, Hodson F, Coady E, Read C, Walton M, Gibbs L, Higginson IJ: Meeting the communication and information needs of chronic heart failure patients. J Pain Symptom Manage 2008;36:149-156.

10. Linden M, Gothe H, Ormel J: Pathways to care and psychological problems of general practice patients in a "gate keeper" and an "open access" health care system: A comparison of Germany and the Netherlands. Soc Psychiatry Psychiatr Epidemiol 2003;38:690-697.

11. Francke AL, Kerkstra A: Palliative care services in The Netherlands: A descriptive study. Patient Educ Couns 2000;4:23-33.

12. Pereira JL, Cantin B, Beauverd M, Zulian GB: [Competencies in palliative care: What should the physicians be able to do?]. Rev Med Suisse 2008;4:454-457.

13. Groot MM, Vernooij-Dassen MJ, Crul BJ, Grol RP: General practitioners (GPs) and palliative care: perceived tasks and barriers in daily practice. Palliat Med 2005;19:111-118.

14. Mitchell GK: How well do general practitioners deliver palliative care? A systematic review. Palliat Med 2002;16: 457-464.

15. Peruselli C, Di GP, Toscani F, Gallucci M, Brunelli C, Costantini M, Tamburini M, Paci E, Miccinesi G, Addington-Hall JM, Higginson IJ: Home palliative care for terminal cancer patients: A survey on the final week of life. Palliat Med 1999;13:233-241.

16. Burge FI, Lawson B, Johnston G: Home visits by family physicians during the end-of-life: Does patient income or residence play a role? BMC Palliat Care 2005;4:1.

17. Borgsteede SD, Deliens L, van der Wal G, Francke AL, Stalman WA, van Eijk JT: Interdisciplinary cooperation of GPs in palliative care at home: A nationwide survey in The Netherlands. Scand J Prim Health Care 2007;25: 226-231.

18. Burge F, Lawson B, Johnston G. Family physician continuity of care and emergency department use in end-of-life cancer care. Med Care 2003;41:992-1001.
19. Michiels E, Deschepper R, Van Der Kelen G, Bernheim JL, Mortier F, Vander Stichele R, Deliens L: The role of general practitioners in continuity of care at the end of life: a qualitative study of terminally ill patients and their next of kin. Palliat Med 2007;21:409-415.

20. Gadzhanova S, Reed R: Medical services provided by general practitioners in residential aged-care facilities in Australia. Med J Aust 2007;187:92-94.

21. Ogle K, Mavis B, Wang T: Hospice and primary care physicians: Attitudes, knowledge, and barriers. Am J Hosp Palliat Care 2003;20:41-51.

22. Van den Block L, Deschepper R, Bossuyt N, Drieskens K, Bauwens S, Van Casteren V, Deliens L: Care for patients in the last months of life: The Belgian Sentinel Network Monitoring End-of-Life Care study. Arch Intern Med 2008;168: 1747-1754.

23. Voorhees J, Rietjens J, Onwuteaka-Philipsen B, Deliens L, Cartwright C, Faisst K, Norup M, Miccinesi G, van der Heide A: Discussing prognosis with terminally ill cancer patients and relatives: Asurvey of physicians' intentions in seven countries. Patient Educ Couns 2009;77:430-436.

24. Michiels E, Deschepper R, Bilsen J, Mortier F, Deliens L: Information disclosure to terminally ill patients and their relatives: Self-reported practice of Belgian clinical specialists and general practitioners. Palliat Med 2009;23:345353.

25. Pardon K, Deschepper R, Vander Stichele R, Bernheim J, Mortier F, Deliens L: Preferences of advanced lung cancer patients for patient-centred information and decisionmaking: A prospective multicentre study in 13 hospitals in Belgium. Patient Educ Couns 2009;77:421-429.

26. Abarshi E, Echteld M, Van den Block L, Donker G, Deliens L, Onwuteaka-Philipsen B: Transitions between care settings at the end of life in The Netherlands: Results from a nationwide study. Palliat Med 20010;24:166-174.

27. Abarshi E, Onwuteaka-Philipsen B, Donker G, Echteld M, Van den Block L, Deliens L: General practitioner awareness of preferred place of death and correlates of dying in a preferred place: A nationwide mortality follow-back study in the Netherlands. J Pain Symptom Manage 2009;38:568577.

28. Marquet RL, Bartelds A, Visser GJ, Spreeuwenberg P, Peters L: Twenty-five years of requests for euthanasia and physician assisted suicide in Dutch general practice: Trend analysis. BMJ 2003;327:201-202.

29. Donker GA: Continuous morbidity registration at Dutch sentinel stations, 2006. Continuous morbidity registration at Dutch sentinel stations, 2006.

30. Oken MM, Creech RH, Tormey DC, Horton J, Davis TE, McFadden ET, Carbone PP: Toxicity and response criteria of the Eastern Cooperative Oncology Group. Am J Clin Oncol 1982;5:649-655.

31. Portenoy RK, Thaler HT, Kornblith AB, Lepore JM, Friedlander-Klar H, Kiyasu E, Sobel K, Coyle N, Kemeny N, Norton L: The Memorial Symptom Assessment Scale: An instrument for the evaluation of symptom prevalence, characteristics and distress. Eur J Cancer 1994;30A:1326-1336.

32. Mebane EW, Oman RF, Kroonen LT, Goldstein MK: The influence of physician race, age, and gender on physician attitudes toward advance care directives and preferences for end-of-life decision-making. J Am Geriatr Soc 1999;47: 579-591.

33. Travis SS, Moore S, Larsen PD, Turner M: Clinical indicators of treatment futility and imminent terminal decline as 
discussed by multidisciplinary teams in long-term care. Am J Hosp Palliat Care 2005;22:204-210.

34. Zhukovsky DS, Herzog CE, Kaur G, Palmer JL, Bruera E: The impact of palliative care consultation on symptom assessment, communication needs, and palliative interventions in pediatric patients with cancer. J Palliat Med 2009; 12:343-349.

35. Terwee CB, Bot SD, de Boer MR, van der Windt DA, Knol DL, Dekker J, Bouter LM, de Vet HC: Quality criteria were proposed for measurement properties of health status questionnaires. J Clin Epidemiol 2007;60:34-42.

36. Coulombe L: Talking with patients. Is it different when they are dying? Can Fam Physician 1995;41:423-437.

37. Field D: Special not different: General practitioners' accounts of their care of dying people. Soc Sci Med 1998;46: 1111-1120.

38. Holmes SM, Rabow MW, Dibble SL: Screening the soul: Communication regarding spiritual concerns among primary care physicians and seriously ill patients approaching the end of life. Am J Hosp Palliat Care 2006;23:25-33.

39. Murray SA, Kendall M, Boyd K, Sheikh A. Illness trajectories and palliative care. BMJ 2005;330:1007-1011.

40. McCarthy M, Hall JA, Ley M: Communication and choice in dying from heart disease. J R Soc Med 1997;90:128-131.
41. Caldwell PH, Arthur HM, Demers C: Preferences of patients with heart failure for prognosis communication. Can J Cardiol 2007;23:791-796.

42. Abarshi E, Echteld M, Van den Block L, Donker GA, Bossuyt $\mathrm{N}$, Meeusen K: Use of palliative care services and GP visits at the end of life in the Netherlands and Belgium. J Pain Symp Man 2010.

43. Abarshi E, Echteld M, Van den Block L, Donker GA, Deliens L, Ontwuteaka-Phillipsen B. The oldest old and end-of-life GP care in the Dutch community: A nationwide study. Age Aging 2010.

44. RCGP End-of-Life Care Strategy. http://www.rcgp.org .uk/pdf/CIRC_RCGP\%20End\%20of\%20Life $\% 20$ Care $\% 20$ Strategy\%20Document\%.pdf. Accessed October 7, 2010.

Address correspondence to: Ebun Abarshi, M.D.

The EMGO Institute for Health \& Care Research (EMGO+) Department of Public and Occupational Health

VU University Medical Center van der Boechorststraat 7, 1081 BT Amsterdam The Netherlands

E-mail: ebun.abarshi@vumc.nl 